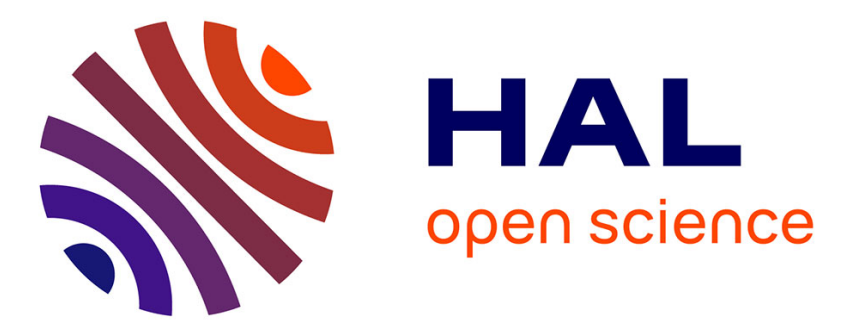

\title{
Chloro complexes of cobalt(II) in aprotic solvents: stability and structural modifications due to solvent effect
}

\author{
Abdelghani Chiboub-Fellah, François Vierling, Jean Meullemeestre, \\ Marie-José Schwing-Weill, Mustayeen Ahmed Khan
}

\section{To cite this version:}

Abdelghani Chiboub-Fellah, François Vierling, Jean Meullemeestre, Marie-José Schwing-Weill, Mustayeen Ahmed Khan. Chloro complexes of cobalt(II) in aprotic solvents: stability and structural modifications due to solvent effect. Journal of Coordination Chemistry, 2009, 62 (10), pp.1572-1583. 10.1080/00958970802663118. hal-03249018

\section{HAL Id: hal-03249018 \\ https://univ-angers.hal.science/hal-03249018}

Submitted on 10 Jun 2021

HAL is a multi-disciplinary open access archive for the deposit and dissemination of scientific research documents, whether they are published or not. The documents may come from teaching and research institutions in France or abroad, or from public or private research centers.
L'archive ouverte pluridisciplinaire HAL, est destinée au dépôt et à la diffusion de documents scientifiques de niveau recherche, publiés ou non, émanant des établissements d'enseignement et de recherche français ou étrangers, des laboratoires publics ou privés. 
This article was downloaded by: [Khan, Mustayeen Ahmed]

On: 7 May 2009

Access details: Access Details: [subscription number 910343239]

Publisher Taylor \& Francis

Informa Ltd Registered in England and Wales Registered Number: 1072954 Registered office: Mortimer House, 37-41 Mortimer Street, London W1T 3JH, UK

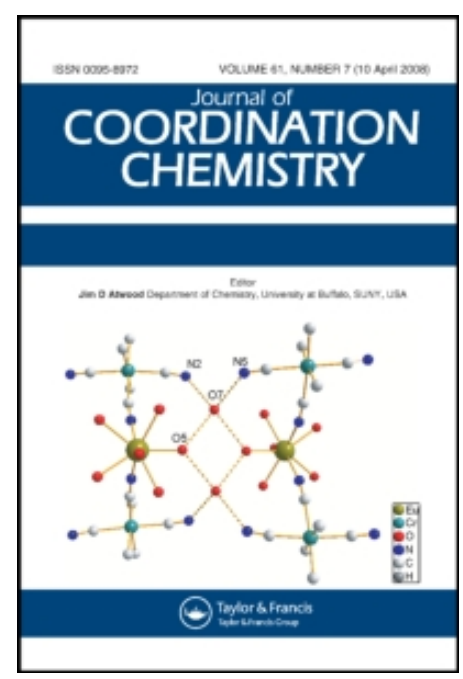

\section{Journal of Coordination Chemistry}

Publication details, including instructions for authors and subscription information:

http://www.informaworld.com/smpp/title content=t713455674

\section{Chloro complexes of cobalt(II) in aprotic solvents: stability and structural} modifications due to solvent effect

Abdelghani Chiboub-Fellah a; François Vierling b; Jean Meullemeestre ${ }^{\text {b; }}$ Marie-José Schwing-Weill b; Mustayeen Ahmed Khan a

a Laboratoire de Chimie de Coordination, SONAS EA 921, IFR149 QUASAV, Faculté de Pharmacie, 49045

Angers cedex 1, France ${ }^{b}$ Ecole de Chimie, Polymères et Matériaux (ECPM), 67087 Strasbourg Cedex 2,

France

First Published:January2009

To cite this Article Chiboub-Fellah, Abdelghani, Vierling, François, Meullemeestre, Jean, Schwing-Weill, Marie-José and Ahmed Khan, Mustayeen(2009)'Chloro complexes of cobalt(II) in aprotic solvents: stability and structural modifications due to solvent effect',Journal of Coordination Chemistry,62:10,1572 - 1583

To link to this Article: DOI: 10.1080/00958970802663118

URL: http://dx.doi.org/10.1080/00958970802663118

\section{PLEASE SCROLL DOWN FOR ARTICLE}

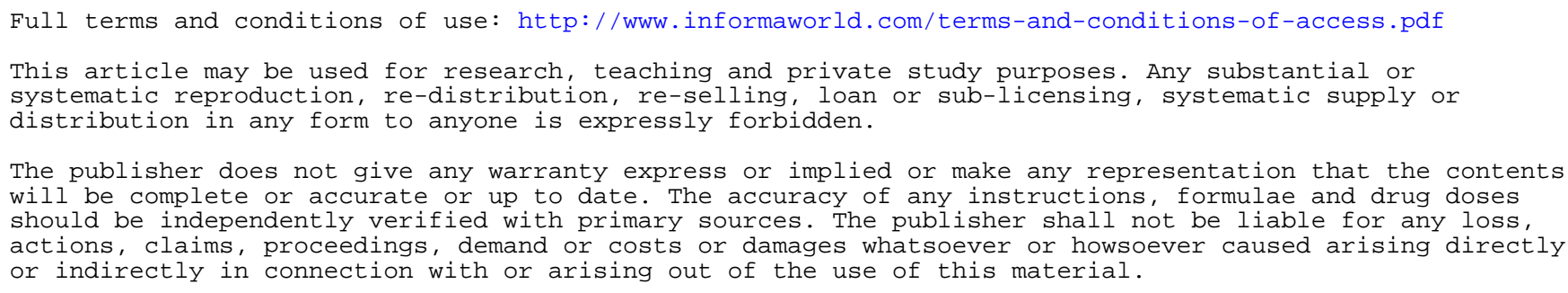




\title{
Chloro complexes of cobalt(II) in aprotic solvents: stability and structural modifications due to solvent effect
}

\author{
ABDELGHANI CHIBOUB-FELLAH†, FRANÇOIS VIERLING†, \\ JEAN MEULLEMEESTRE $\downarrow$, MARIE-JOSÉ SCHWING-WEILL + and \\ MUSTAYEEN AHMED KHAN*† \\ $†$ Laboratoire de Chimie de Coordination, SONAS EA 921, IFR149 QUASAV, \\ Faculté de Pharmacie, 16 bd Daviers, 49045 Angers cedex 1, France \\ FEcole de Chimie, Polymères et Matériaux (ECPM), UMR 7512, 25 rue Becquerel, \\ BP 8, 67087 Strasbourg Cedex 2, France
}

(Received 12 June 2008; in final form 8 September 2008)

\begin{abstract}
Cobalt(II) chloro complexes were studied in aprotic solvents, namely, dimethylsulfoxide (DMSO), dimethylformamide (DMF), and propylene carbonate (PC). The measurements were performed spectrophotometrically in UV-visible-IR region at $25^{\circ} \mathrm{C}$ and at constant ionic strength: $I=1 \mathrm{~mol} \mathrm{~L}^{-1}$ in DMSO and DMF, and $0.1 \mathrm{~mol} \mathrm{~L}^{-1}$ in PC. Different models were tested and the model $[1,2,3,4]$, i.e., that of four mononuclear successive complexes was retained. Stability constants of the identified complexes were determined and they increase inversely with the Gutmann's donor number of the solvents. Calculated electronic spectra are reported and the effect of solvents on the spectral properties are discussed. The symmetry of tetrachlorocobaltate is strictly $\mathrm{T}_{\mathrm{d}}$.
\end{abstract}

Keywords: Cobalt(II) chloro complexes; Spectrophotometry; Aprotic solvents; Stability constants; Structural modifications

\section{Introduction}

The behavior of copper(II) chloro complexes in numerous organic solvents [1-10] were characterized by the presence of four mononuclear copper complexes, the exception being dimethylformamide (DMF) and dimethylsulfoxide (DMSO), where the dichloro complex is absent. The apparent stability constants, $\beta_{j}$, of the identified complexes were calculated and, in some cases, interesting relationships between the stability constants and the molecular weight or the dielectric constant of the solvents reported $[10,11]$. Detailed results of nickel(II) chloro complexes in DMF, DMSO, and propylene carbonate (PC) have also been reported [12]. In this system the monochloro complex is predominant and attains $70 \%$ formation in DMF and DMSO, and up to $90 \%$ in PC.

Gutmann et al. [13-15] did a detailed quantitative pioneering study of the chloro complexes of cobalt(II), nickel(II), and copper(II) in solvents such as trimethylphosphate (TMP), acetonitrile (AN), DMF, and PC. A crystallographic and spectroscopic

*Corresponding author. Email: mustayeen.khan@univ-angers.fr 
study of halide compounds of cobalt(II) shows that the structure of $\mathrm{CoCl}_{2}$ entities can be either octahedral or tetrahedral [16]. Schriver [17] reported a spectrophotometric study of chloro and thiocyanato complexes of cobalt(II) in DMSO using the method of molecular ratio. Licheri et al. [18] have shown the presence of tri- and tetrachloro nickel complexes in solution, compared to those of higher complex formation in cobalt.

Recently, Djekic et al. [19] have determined stability constants of cobalt(II) chloro complexes with triphenylphosphine ligands in butan-1-ol, DMF, and AN. Hirose [20] has described a general approach to determine stability constants by combining titration and spectroscopic methods. Cobalt(II) complexes have also been characterized by X-ray diffraction and tested as catalysts for olefin polymerization [21].

In this work, we use the same methodology as in our earlier publications to investigate the behavior of cobalt(II) chloride complexes in DMF, DMSO, and PC to observe solvent effects on spectroscopic properties of the identified complexes and subsequent structural modifications. The equilibrium studied, therefore, is:

$$
\mathrm{Co}^{2+}+j \mathrm{Cl}^{-} \rightleftharpoons \mathrm{CoCl}_{j}^{(j-2)-}
$$

and for the identified complexes in the three aprotic solvents, the overall stability constants, $\beta_{j}$, were calculated:

$$
\beta_{j}=\left[\mathrm{CoCl}_{j}^{(j-2)-}\right] /\left[\mathrm{Co}^{2+}\right] \cdot\left[\mathrm{Cl}^{-}\right]^{j}
$$

The relationship between the overall stability constants, $\beta_{j}$, and the stepwise stability constants, $K_{j}$, is:

$$
\beta_{j}=K_{1} \times K_{2} \times K_{3} \times \cdots \times K_{j}
$$

or

$$
K_{j}=\frac{\beta_{j}}{\beta_{j-1}}
$$

\section{Experimental}

\subsection{Reagents}

The aprotic solvents were used after several purification steps in order to eliminate organic compounds or products resulting from possible photochromic degradation. Solvents were considered to be anhydrous if the water content was less than $250 \mathrm{ppm}$. Dried DMSO (Fluka) was purified by two distillations at $45^{\circ} \mathrm{C}$ under reduced pressure ( $1 \mathrm{~mm} \mathrm{Hg}$ ) and over a large $\mathrm{CaH}_{2}$ surface; less than $100 \mathrm{ppm}$ of $\mathrm{H}_{2} \mathrm{O}$ were found in the purified DMSO. Elleb et al. [1] showed that small quantities of water do not modify either the stability of the solvent and samples of solutions under study, or their absorption values, within $48 \mathrm{~h}$. In any case, the solvent was used immediately after purification in order to establish identical experimental conditions for all investigated systems. DMF (Fluka) was distilled under reduced pressure below $80^{\circ} \mathrm{C}$, which corresponds to onset of decomposition of the solvent. The redistilled DMF contains less than $250 \mathrm{ppm}$ of $\mathrm{H}_{2} \mathrm{O}$ and its purity was checked by conductivity measurements according to the recommendation of Juillard [22]. Propylene carbonate (Fluka) was 
purified in several steps using the method of Gossé and Denat [23]. After $12 \mathrm{~h}$ contact with $\mathrm{KMnO}_{4}$, the remaining solid was filtered and the dissolved permanganate eliminated by heating for $4 \mathrm{~h}$ at $120^{\circ} \mathrm{C}$. After cooling, $\mathrm{MnO}_{2}$ and the oxidized products (propylene glycol, allyl alcohol, and propylene oxide) were separated by filtration. Rapid filtration was performed at $15 \mathrm{~mm} \mathrm{Hg}$ pressure and the solution was passed through an $\mathrm{Al}_{2} \mathrm{O}_{3}$ column in order to remove acidic impurities. The remaining solvent was then redistilled at $68-70^{\circ} \mathrm{C}(1 \mathrm{~mm} \mathrm{Hg})$. The yield is $c a .50 \%$ and $\mathrm{PC}$ has a $\mathrm{H}_{2} \mathrm{O}$ content $<100$ ppm.

Due to absorptions of both DMSO and DMF, the measurements were limited to wavelengths greater than 280 and $260 \mathrm{~nm}$, respectively. PC is transparent in the UV but limited below $1400 \mathrm{~nm}$ in the near IR - the more specific d-d transitions range in the investigated complexes.

Recrystallized $\mathrm{LiCl}$ (Fluka) was used for the ligand with $\mathrm{LiClO}_{4}$ (Fluka) to maintain a constant ionic strength, $I$, at $1 \mathrm{~mol} \mathrm{~L}^{-1}$ in DMSO and DMF solutions. In $\mathrm{PC}$, due to solubility, recrystallized $\mathrm{Et}_{4} \mathrm{NCl}$ and $\mathrm{Et}_{4} \mathrm{NClO}_{4}$ (Fluka) were used at $I=0.1 \mathrm{~mol} \mathrm{~L}^{-1}$.

The cobalt ion was introduced as $\mathrm{Co}\left(\mathrm{ClO}_{4}\right)_{2} \cdot 6 \mathrm{H}_{2} \mathrm{O}$. Synthesis of $\mathrm{Co}(\mathrm{solv})_{x}\left(\mathrm{ClO}_{4}\right)_{2}$, where $x$ is 4 or 6 , is practical in DMSO and DMF but dangerous due to possible formation of unstable alkyl perchlorates. The use of $\mathrm{Co}\left(\mathrm{ClO}_{4}\right)_{2} \cdot 6 \mathrm{H}_{2} \mathrm{O}$ instead of anhydrous $\mathrm{Co}\left(\mathrm{ClO}_{4}\right)_{2}$ in the solvents under study has no significant effect on the absorption spectra. The metal ion content is controlled through complexometric titration with EDTA and murexide as indicator at $\mathrm{pH}=8.0$ [24].

\subsection{Measurements}

Measurements were performed with a Cary 17D spectrophotometer connected with a Cary Interface to a routine printer (Star LC-10) for data collection. The concentrations of the metal ion never exceeded $10^{-2} \mathrm{~mol} \mathrm{~L}^{-1}$ in order to guarantee accurate absorbance values between 0.2 and 2.0. The spectra were run immediately after mixing the reagents and took less than $1 \mathrm{~min}$ to obtain the absorbance curve. The solutions were found to be stable for at least $30 \mathrm{~min}$ after mixing. Sets of $(N, L)$ data points were collected: $N$ and $L$ were the number of solutions and of wavelengths, respectively. A set of $(N, L)$ data points close to $(20,40)$ collected in the visible region is sufficient for numerical analysis and used for refinement of the constants.

$\begin{array}{lll}\text { - In the DMSO system: } & (N, L)_{\mathrm{vis}}=(21,40) & 450 \leq \lambda \leq 730 \mathrm{~nm} \\ & (N, L)_{\mathrm{nir}}=(10,21) & 1260 \leq \lambda \leq 1660 \mathrm{~nm} \\ & (N, L)_{\mathrm{vis}}=(20,35) & 450 \leq \lambda \leq 730 \mathrm{~nm} \\ \text { - In the DMF system: } & (N, L)_{\mathrm{nir}}=(11,17) & 1160 \leq \lambda \leq 1840 \mathrm{~nm} \\ & (N, L)_{\mathrm{uv}}=(14,10) & 210 \leq \lambda \leq 255 \mathrm{~nm} \\ & (N, L)_{\mathrm{vis}}=(14,39) & 480 \leq \lambda \leq 720 \mathrm{~nm}\end{array}$

\subsection{Calculations}

The whole set of spectrophotometric data, $(N, L)_{\text {vis }}+(N, L)_{\text {ir }}$, was analyzed using a multiwavelength program, details of which were given in earlier publications [1, 25]. For a given model, this program calculates simultaneously two sets of optimized 
parameters: the overall stability constants, $\beta_{j}$, and the extinction coefficients, $\varepsilon_{j}$, of all species involved in complexation. The quality of the fit is judged for a given model from the value of $\langle\sigma\rangle$, the quadratic mean of the standard deviation at each wavelength, $\sigma_{L}$, obtained in the calculation: $\langle\sigma\rangle=\left(\Sigma \sigma_{L}^{2} / L\right)^{1 / 2}$. It is necessary, in all programs treating multicomponent systems, to postulate supplementary approximations in the vicinity of the minimum of the least squares function and complementary statistical criteria in order to obtain satisfactory values for the deviations of the constants [25].

\section{Results and discussion}

Absorption bands for octahedral and tetrahedral complexes of cobalt(II) have been characterized in the solid state [16] and aqueous solution [26]. ForCo $\left(\mathrm{H}_{2} \mathrm{O}\right)_{6}^{2+}$, absorption spectra of the pink solution, characteristic of $\mathrm{O}_{h}$ symmetry, has three principal maxima in the visible and near-IR: at $1250 \mathrm{~nm}\left(1.5 \mathrm{~L} \mathrm{~mol}^{-1} \mathrm{~cm}^{-1}\right)$ $\left({ }^{4} \mathrm{~T}_{1 \mathrm{~g}}(\mathrm{~F}) \rightarrow{ }^{4} \mathrm{~T}_{2 \mathrm{~g}}(\mathrm{~F})\right)$, at $630 \mathrm{~nm}\left(0.3 \mathrm{~L} \mathrm{~mol}^{-1} \mathrm{~cm}^{-1}\right)\left({ }^{4} \mathrm{~T}_{1 \mathrm{~g}}(\mathrm{~F}) \rightarrow{ }^{4} \mathrm{~A}_{2 \mathrm{~g}}(\mathrm{~F})\right)$, and at $510 \mathrm{~nm}$ $\left(4.9 \mathrm{~L} \mathrm{~mol}^{-1} \mathrm{~cm}^{-1}\right)\left({ }^{4} \mathrm{~T}_{1 \mathrm{~g}}(\mathrm{~F}) \rightarrow{ }^{4} \mathrm{~T}_{1 \mathrm{~g}}(\mathrm{P})\right)$, all with weak intensities. During tetrahedral complex formation, blue solutions characteristic of $\mathrm{T}_{\mathrm{d}}$ symmetry lead to spectra where the absorption bands undergo a very clear bathochromic shift: the spectrum of $\mathrm{CoCl}_{4}^{2-}$ ion presents a complicated "enveloped" absorption band where the transitions situated at 635, 670, and $695 \mathrm{~nm}$ acquire intensity resulting from spin-orbit coupling [16].

These spectroscopic properties have been taken into consideration in order to identify the number and the nature of the chloro complexes of cobalt(II) in the three aprotic solvents studied, and to determine their stability constants and observe the solvent effects, if any, on the spectra.

\subsection{Experimental spectra}

With increase in concentration of chloride, the color of the solutions change progressively from pink-purple to intense blue, denoting successive formation of chloro complexes. This also allows distinguishing the characteristic concentration zones of the octahedral and tetrahedral species. Spectra presented in figures 1-3 correspond, respectively, to the absorption of the solutions, $\mathrm{Co}(\mathrm{II})-\mathrm{Li}^{+}\left(\mathrm{ClO}_{4}^{-}, \mathrm{Cl}^{-}\right) 1 \mathrm{~mol} \mathrm{~L}^{-1}$ DMSO; $\quad \mathrm{Co}(\mathrm{II})-\mathrm{Li}^{+}\left(\mathrm{ClO}_{4}^{-}, \quad \mathrm{Cl}^{-}\right) \quad 1 \mathrm{~mol} \mathrm{~L}^{-1}-\mathrm{DMF} ; \quad \mathrm{Co}(\mathrm{II})-\mathrm{Et}_{4} \mathrm{~N}^{+}\left(\mathrm{ClO}_{4}^{-}, \quad \mathrm{Cl}^{-}\right)$ $0.1 \mathrm{~mol} \mathrm{~L}^{-1}-\mathrm{PC}$.

The spectrum of a solution of cobalt(II) perchlorate is characterized by a large band of very weak intensity $\left(\varepsilon_{0}<20 \mathrm{~L} \mathrm{~mol}^{-1} \mathrm{~cm}^{-1}\right)$ at $520 \mathrm{~nm}$. A clear hypsochromic shift is observed when going from DMSO $(530 \mathrm{~nm})$ to DMF $(520 \mathrm{~nm})$ and PC $(510 \mathrm{~nm})$. With addition of small quantities of chloride, a slight bathochromic shift of the noncomplexed solvated cobalt ion band is noted along with a hardly perceptible increase in absorption. These changes indicate the formation of the first chloro complex.

For chloride/metal concentration ratio less than 2, important changes are seen in the absorption spectra. A large absorption band of increasing intensity appears between 580 and $700 \mathrm{~nm}$, with a maximum at $605 \mathrm{~nm}$. Another band of twice the intensity is 


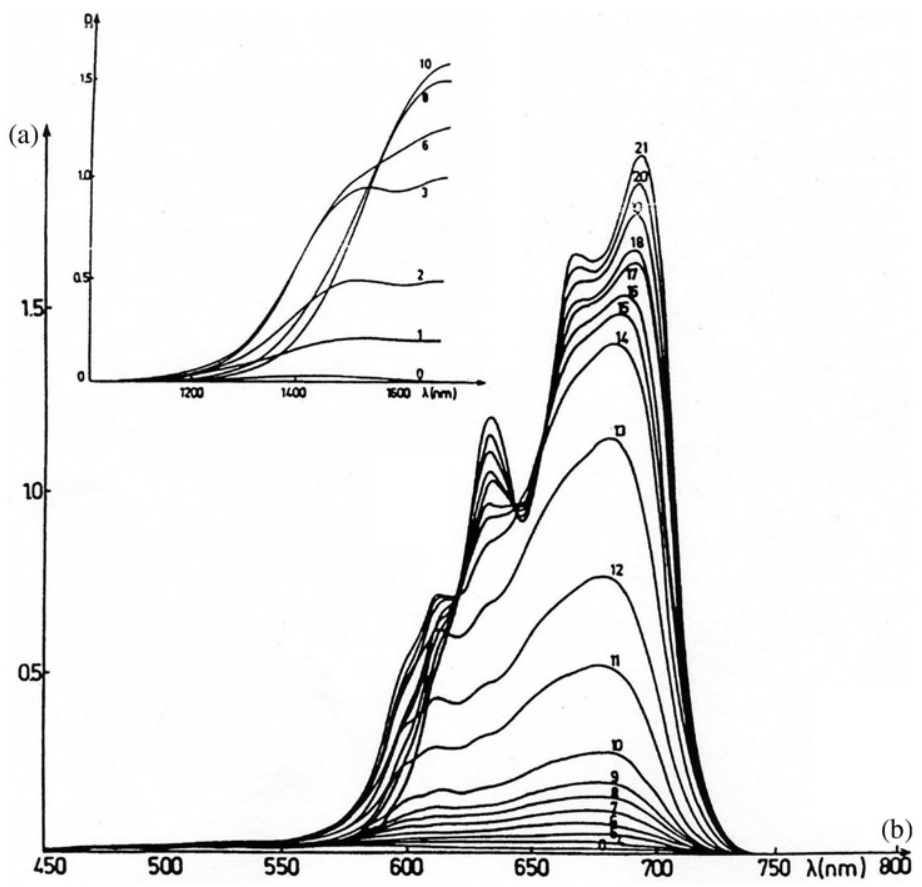

Figure 1. Absorption spectra of cobalt(II)-lithium chloride solutions in DMSO. (a): Visible: $\left[\mathrm{Co}^{2+}\right]=$ $5 \times 10^{-3} \mathrm{~mol} \mathrm{dm}^{-3}, l_{\text {cell }}=0.5 \mathrm{~cm} \mathrm{Spectra} / 10^{3} \times \mathrm{mol} \mathrm{dm}^{-3}: 0 / 0,4 / 3,5 / 4,6 / 5,7 / 6,8 / 7,9 / 8,10 / 10,11 / 15,12 / 20$, $13 / 30,14 / 50,15 / 75,16 / 100,17 / 150,18 / 200,19 / 300,20 / 500,21 / 1000$. (b): Infrared: $\left[\mathrm{Co}^{2+}\right]=10^{-2} \mathrm{~mol} \mathrm{dm}^{-3}$, $l_{\text {cell }}=2 \mathrm{~cm} \mathrm{Spectra} / 10^{2} \times \operatorname{mol~dm}^{-3}: 0 / 0,1 / 1,2 / 2,3 / 4,6 / 10,8 / 50,10 / 100$.

observed at $675 \mathrm{~nm}$. These changes indicate the presence of the dichloro complex [figure 2(a), spectra 3-12].

The absorption spectra are totally modified for solutions rich in chloride concentrations, where the molecular ratio is greater than 4. Absorption is negligible in UV up to $550 \mathrm{~nm}$. Between 550 and $730 \mathrm{~nm}$, there are four clear maxima at 600, 630, 665 , and $690 \mathrm{~nm}$, characteristic of tetrahedral cobalt [16]. At the same concentration ratio $(4<R<100)$, an equilibrium between $\mathrm{CoCl}_{3}^{-}$and $\mathrm{CoCl}_{4}^{2-}$ is observed by the presence of isosbestic points at 618, 642, and $653 \mathrm{~nm}$ [figure 2(a), spectra 14-22].

The variation of experimental spectra is nearly the same in DMSO and DMF. In PC, the absorption band is stabilized when the chloride/metal concentration ratio is greater than 4 [figure 3, spectra 14-22]. In this medium, the final spectrum corresponds to the spectrum of $\mathrm{CoCl}_{4}^{2-}$, indicating $100 \%$ formation of this complex. Taking into consideration the interference caused by the absorption of solvents below $260 \mathrm{~nm}$, the charge transfer bands of cobalt(II) chloro complexes were characterized only in PC. In this medium, there is a regular increase in the absorption intensity with increasing ligand concentration with a slight hypsochromic shift of the maximum at $240 \mathrm{~nm}$. For concentrated solutions, $\mathrm{CoCl}_{4}^{2-}$ is observed along with isosbestic points showing equilibrium between the two most coordinated complexes.

Spectral variations were also recorded in the near IR for DMSO and DMF. The octahedral ion $\mathrm{Co}(\mathrm{DMF}){ }_{6}^{2+}\left({ }^{4} \mathrm{~T}_{1 \mathrm{~g}}(\mathrm{~F}) \rightarrow{ }^{4} \mathrm{~T}_{2 \mathrm{~g}}(\mathrm{~F})\right)$ has a very large maximum of very low intensity centered between 1240 and $1260 \mathrm{~nm}$ (figure 2). The addition of chloride results in a spectacular change in the absorption spectra with the maximum undergoing 


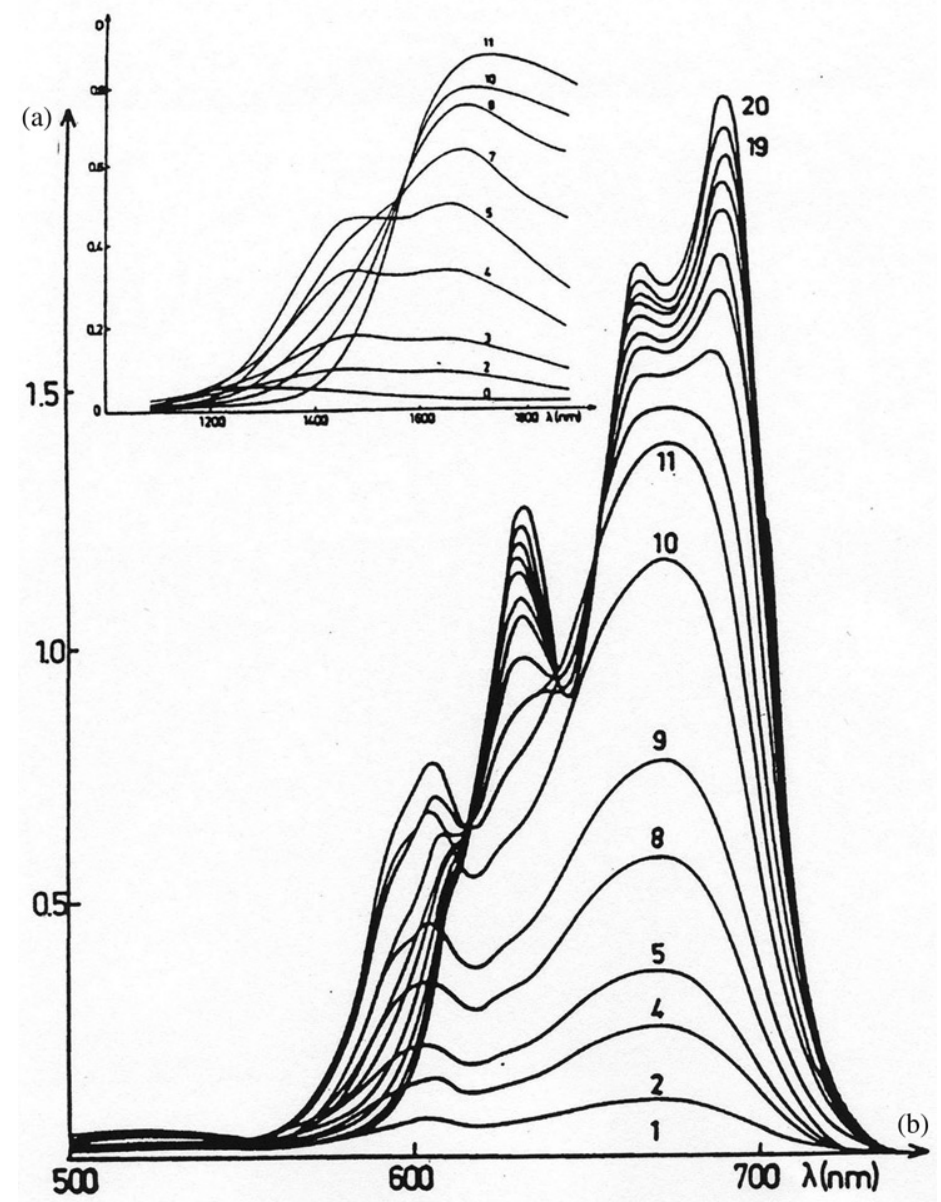

Figure 2. Absorption spectra of cobalt(II)-lithium chloride solutions in DMF. (a): Visible: $\left[\mathrm{Co}^{2+}\right]=$ $5 \times 10^{-3} \mathrm{~mol} \mathrm{dm}^{-3}, l_{\text {cell }}=0.5 \mathrm{~cm}$ Spectra $/ 10^{3} \times \mathrm{mol} \mathrm{dm}^{-3}: 1 / 1,2 / 2,4 / 4,5 / 5,8 / 8,9 / 10,10 / 15,11 / 20,12 / 30$, $13 / 50,14 / 75,15 / 100,16 / 150,17 / 200,18 / 300,19 / 500,20 / 1000$. (b): Infrared: $\left[\mathrm{Co}^{2+}\right]=10^{-2} \mathrm{~mol} \mathrm{dm}^{-3}$, $l_{\text {cell }}=1 \mathrm{~cm} \mathrm{Spectra} / 10^{2} \times \operatorname{mol~dm}^{-3}: 0 / 0,2 / 0.5,3 / 1,4 / 2,5 / 3,7 / 5,8 / 10,10 / 20,11 / 100$.

a bathochromic shift of nearly $500 \mathrm{~nm}$. The absence of isosbestic points for solutions of lower chloride concentrations (figure 2, spectra 1-7), as well as the regular shift of the maxima, clearly show the presence of at least three complexes, the last one characterized by two distinct and well-separated maxima (1480 and $1660 \mathrm{~nm})$. The most coordinated species presents a single maximum situated around $1740 \mathrm{~nm}$.

\subsection{Number of chloro complexes}

Preliminary analysis of the experimental spectra document indicates presence of three complexes in each of the three solvents under study. The most substituted complex is $\mathrm{CoCl}_{4}^{2-}$, which is clearly identified by the characteristic absorption bands of the tetrahedral configuration. Isosbestic points observed in solutions with high ligand concentrations indicate equilibrium between $\mathrm{CoCl}_{3}^{-}$and $\mathrm{CoCl}_{4}^{2-}$. On the other hand, 


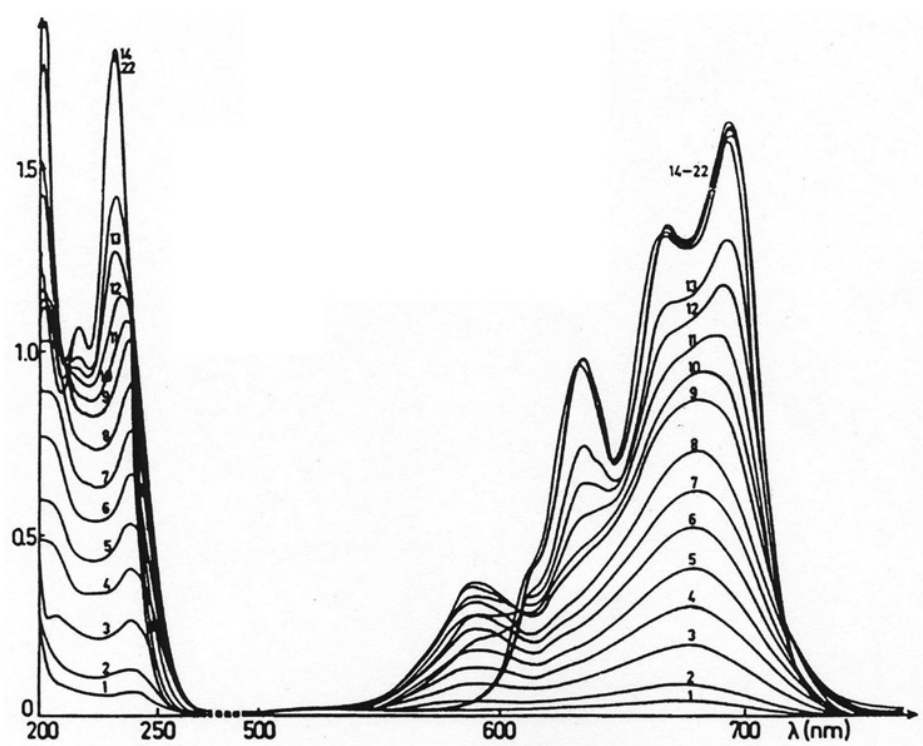

Figure 3. Absorption spectra of cobalt(II)-tetraethyl-ammonium chloride solutions in PC. UV-Visible: $\left[\mathrm{Co}^{2+}\right]=2.10^{-3} \mathrm{~mol} \mathrm{dm}^{-3}, l_{\text {cell }}=1 \mathrm{~cm}$ Spectra $/ 10^{3} \times \mathrm{mol} \mathrm{dm}^{-3}: 1 / 0.375,2 / 0.75,3 / 1.5,4 / 2.25,5 / 3,6 / 3.75,7 / 4.5$, $8 / 5.25,9 / 6,10 / 6.375,11 / 6.75,12 / 7.15,13 / 7.5,14 / 9,15 / 10.5,16 / 12,17 / 13.5,18 / 15,19 / 30,20 / 45,21 / 60,22 / 75$.

it is difficult to say if the absorbance variations of solutions of low ligand concentrations are due to one or two supplementary species $\mathrm{CoCl}_{2}$ and/or $\mathrm{CoCl}^{+}$.

The matrix rank treatment of Hugus and El-Awady [27], applied to the experimental data, allows the determination of the minimum number of absorbing species. The calculations indicate a minimum of three absorbing species - four in PC. Taking into consideration that the noncomplexed solvated cobalt ion has a detectable absorption band compared to complexed cobalt, the minimum number of complexes would be two to three in case of PC, which, however, contradicts the form and variation of experimental spectra. Moreover, calculations on theoretical models using two complexes: $[1,4],[2,4]$, or $[3,4]$, that is, the mono- and tetra-, the di- and tetra-, or the tri- and tetrachloro complexes, respectively, lead to unsatisfactory results for the whole experimental data.

\subsection{Stability constants of cobalt(II) chloro complexes}

In conformity with the preceding discussion, the following theoretical models were tested.

- Three models of three mononuclear complexes: [2,3,4], [1,2,4], and [1,3,4], i.e., respectively, the di-, tri- and tetra-; the mono-, di- and tetra-; the mono-, tri- and tetrachloro complexes.

- One model of four successive mononuclear complexes: [1, 2, 3, 4].

Simultaneous determination of the parameters $\beta_{j}$ and $\varepsilon_{j}$ leads to the best values of stability constants, specific extinction coefficients, and the quadratic mean $\langle\sigma\rangle$ related to regions of wavelengths. The intervals of uncertainty for the determined values were 
calculated by the method proposed by Byé [28]. All these numerical results, for the three solvents studied, are assembled in tables 1-3.

As expected, the model $[1,2,3,4]$ leads to lower values for $\langle\sigma\rangle$ compared to the models with three complexes. This is normally the case when there are more parameters to be optimized. The numerical criterion, therefore, is sufficient to easily eliminate the models $[2,3,4]$ and $[1,2,4]$. Indeed, working under the hypothesis of successive formation of complexes, it is difficult to imagine that the metal-chloride bonds are stabilized to the extent that the most easily substituted species is attributed zero as stability constant. Moreover, it is unlikely that there is only one equilibrium of $\mathrm{CoCl}_{2}$ and $\mathrm{CoCl}_{4}^{2-}$ for solutions of high ligand concentrations.

Interpretation of data under the hypothesis of the model [1,3,4] is, as regards the numerical criterion, an acceptable result and is comparable to that obtained with model $[1,2,3,4]$. The difference of $\langle\sigma\rangle$ between the two is small (0.010). Gutmann explained the absence of dichloro complex in the model $[1,3,4]$ on the basis that the solvent and the ligand have similar donor numbers favoring dissociation into mono- and trichloro complexes [29].

Table 1. Calculated stability constants for different models of cobalt(II) chloro complexes in DMSO.

\begin{tabular}{lcccc}
\hline & {$[2,3,4]$} & {$[1,2,4]$} & {$[1,3,4]$} & {$[1,2,3,4]$} \\
\hline$\beta_{1}$ & - & $(3.1 \pm 1.0) 10^{3}$ & $(3.2 \pm 0.6) 10^{2}$ & $(1.6 \pm 1.1) 10^{3}$ \\
$\beta_{2}$ & $(6.3 \pm 1.8) 10^{5}$ & $(1.2 \pm 0.5) 10^{5}$ & - & $(8.6 \pm 6.4) 10^{4}$ \\
$\beta_{3}$ & $(1.1 \pm 0.5) 10^{8}$ & - & $(6.6 \pm 1.6) 10^{6}$ & $(9.1 \pm 5.4) 10^{6}$ \\
$\beta_{4}$ & $(8.9 \pm 8.0) 10^{8}$ & $(1.7 \pm 1.6) 10^{7}$ & $(5.6 \pm 3.2) 10^{7}$ & $(8.3 \pm 7.5) 10^{7}$ \\
$\langle\sigma\rangle$ & 0.078 & 0.081 & 0.049 & 0.043 \\
\hline
\end{tabular}

Note: $(N, L)$ : visible $=(21,40)$; near $\operatorname{IR}=(10,21)$.

Table 2. Calculated stability constants for different models of cobalt(II) chloro complexes in DMF.

\begin{tabular}{lcccc}
\hline & {$[2,3,4]$} & {$[1,2,4]$} & {$[1,3,4]$} & {$[1,2,3,4]$} \\
\hline$\beta_{1}$ & - & $(4.3 \pm 3.9) 10^{2}$ & $(7.8 \pm 7.0) 10^{2}$ & $(1.2 \pm 0.7) 10^{3}$ \\
$\beta_{2}$ & $(5.1 \pm 4.1) 10^{5}$ & $(1.5 \pm 1.0) 10^{5}$ & - & $(1.2 \pm 0.9) 10^{7}$ \\
$\beta_{3}$ & $(2.6 \pm 1.2) 10^{9}$ & - & $(2.3 \pm 0.8) 10^{9}$ & $(1.1 \pm 0.7) 10^{10}$ \\
$\beta_{4}$ & $(6.6 \pm 2.3) 10^{10}$ & $(6.4 \pm 5.3) 10^{7}$ & $(6.0 \pm 2.0) 10^{10}$ & $(3.2 \pm 1.7) 10^{11}$ \\
$\langle\sigma\rangle$ & 0.054 & 0.076 & 0.045 & 0.037 \\
\hline
\end{tabular}

Note: $(N, L)$ : visible $=(20,35)$; near $\operatorname{IR}=(11,17)$.

Table 3. Calculated stability constants for different models of cobalt(II) chloro complexes in PC.

\begin{tabular}{|c|c|c|c|c|}
\hline & {$[2,3,4]$} & {$[1,2,4]$} & {$[1,3,4]$} & {$[1,2,3,4]$} \\
\hline$\beta_{1}$ & - & $(3.5 \pm 2.7) 10^{3}$ & $(3.1 \pm 2.8) 10^{3}$ & $(1.8 \pm 1.3) 10^{6}$ \\
\hline$\beta_{2}$ & $(9.1 \pm 8.1) 10^{7}$ & $(1.1 \pm 1.0) 10^{2}$ & - & $(6.5 \pm 2.2) 10^{11}$ \\
\hline$\beta_{3}$ & $(1.2 \pm 1.0) 0^{14}$ & - & $(2.9 \pm 2.8) 10^{14}$ & $(5.3 \pm 2.7) 10^{17}$ \\
\hline$\beta_{4}$ & $(2.2 \pm 1.9) 0^{18}$ & $(7.1 \pm 6.4) 10^{14}$ & $(4.6 \pm 4.1) 10^{18}$ & $(2.3 \pm 2.1) 10^{22}$ \\
\hline$\langle\sigma\rangle$ & 0.094 & 0.143 & 0.067 & 0.060 \\
\hline
\end{tabular}

Note: $(N, L): U V=(14,10)$; visible $=(14,39)$. 
Table 4. The logarithms of the overall stability constants, $\beta_{j}$, and the stepwise stability constants, $K_{j}$, of the chloro complexes of cobalt(II) for the model $[1,2,3,4]$ in aprotic medium. The numbers given below the column headings of the solvents are the dielectric constants of the solvents, $\varepsilon_{r}$, and Gutmann's Donor Numbers, DN: $\left(\varepsilon_{r} / \mathrm{DN}\right)$.

\begin{tabular}{lccr}
\hline & DMSO 45/29.8 & DMF 36.1/26.6 & PC 69/15.1 \\
\hline $\log \beta_{1}\left(\log K_{1}\right)$ & $3.2(3.2)$ & $3.1(3.1)$ & $6.3(6.3)$ \\
$\log \beta_{2}\left(\log K_{2}\right)$ & $4.9(1.7)$ & $7.0(3.9)$ & $11.8(5.5)$ \\
$\log \beta_{3}\left(\log K_{3}\right)$ & $6.9(2.0)$ & $10.0(3.0)$ & $17.7(5.9)$ \\
$\log \beta_{4}\left(\log K_{4}\right)$ & $7.9(1.0)$ & $11.5(1.5)$ & $22.4(4.7)$ \\
\hline
\end{tabular}

Taking into consideration the mathematical criterion of $\langle\sigma\rangle$, the model $[1,2,3,4]$ is retained; table 4 gives the logarithmic values of the overall stability constants of the complexes.

Comparison with literature values for the stability constants, especially of the monoand the dichloro complex, show that they are higher in organic solvents than in aqueous medium. The same pattern is observed in case of the chloro complexes of copper(II) in water [30] and in organic medium [1, 31, 32].

No correlation is observed for stability with respect to the dielectric constant of the solvents. However, it is interesting to note that stability increases significantly with decrease in Gutmann's donor numbers of the solvents (table 4).

\subsection{Electronic spectra of the cobalt(II) chloro complexes}

Using the calculated values of $\beta_{j}$, the specific extinction coefficients, $\varepsilon_{j}$, were calculated for all the species in order to determine the electronic spectra, and these values are presented in table 5 .

3.4.1. Noncomplexed cobalt(II). In the visible spectrum, cobalt(II) is characterized by a low intensity band around $510 \mathrm{~nm}$ in PC, and this band is displaced towards the red by $10 \mathrm{~nm}$ in DMF and by $20 \mathrm{~nm}$ in DMSO. The absorption maximum in the UV, determined only in PC, is at wavelength less than $220 \mathrm{~nm}$. In the IR region, the solvate has a band at $1260 \mathrm{~nm}$ in PC, $1280 \mathrm{~nm}$ in DMF, and at $1435 \mathrm{~nm}$ in DMSO. For a given ion and given structure, the d-d transition bands depend on the electrostatic field of the coordinated ligands, measured by the crystal field parameter $\Delta=10 \mathrm{Dq}$. A bandshift towards the violet region, i.e., hypsochromic shift, shows an increase of Dq, whereas a shift to the red, i.e., bathochromic, indicates decrease of Dq. In the present case, this bathochromic shift of $175 \mathrm{~nm}$ in the near IR, and of $20 \mathrm{~nm}$ in the visible, from PC to DMSO defines the spectrochemical sequence of the octahedral structure of Cobalt(solv $)_{6}^{2+}$ as follows:

$$
\mathrm{Dq}(\mathrm{DMSO})<\mathrm{Dq}(\mathrm{DMF})<\mathrm{Dq}(\mathrm{PC})
$$

This sequence is in the inverse order of the donor numbers of the three solvents.

3.4.2. Monochloro complex. $\mathrm{CoCl}^{+}$has a single charge transfer band, calculated at $240 \mathrm{~nm}$ in PC. In the visible, this complex presents two bands of comparable intensities in the three solvents (table 5). A bathochromic shift of the first band from 535 to $590 \mathrm{~nm}$ 
Table 5. Absorptions of the chloro complexes of cobalt(II) in aprotic media: $\lambda_{\max }$ in $\mathrm{nm}\left(\varepsilon_{j \max }\right.$ in $\left.\mathrm{L} \mathrm{mol}^{-1} \mathrm{~cm}^{-1}\right)$; sh: shoulder peak.

\begin{tabular}{|c|c|c|c|}
\hline Species & DMSO & DMF & $\mathrm{PC}$ \\
\hline $\mathrm{Co}(\text { solv })_{6}^{2+} \quad \mathrm{O}_{\mathrm{h}}$ & $\begin{array}{c}530(11) \\
1435(1.4)\end{array}$ & $\begin{array}{c}520(18.2) \\
1280(5.7)\end{array}$ & $\begin{array}{c}>210 \\
510(8.4) \\
1260(2.5)\end{array}$ \\
\hline $\mathrm{CoCl}^{+}$ & $\begin{array}{l}535(14) \\
670(12)\end{array}$ & $\begin{array}{c}545(38) \\
620(22) \\
1380(8)\end{array}$ & $\begin{array}{l}240(950) \\
590(88) \\
675(140)\end{array}$ \\
\hline $\mathrm{CoCl}_{2}$ & $\begin{array}{c}520(10) \\
610(270) \\
660 \mathrm{sh} \\
680(490)\end{array}$ & $\begin{array}{c}530(11) \\
606(180) \\
660 \mathrm{sh} \\
670(320) \\
1480(33) \\
1640(36)\end{array}$ & $\begin{array}{l}232(1870) \\
635(132) \\
670(260) \\
685(260)\end{array}$ \\
\hline $\mathrm{CoCl}_{3}^{-}$ & $\begin{array}{l}610(336) \\
655 \mathrm{sh} \\
680(586)\end{array}$ & $\begin{array}{c}605(340 \\
655 \mathrm{sh} \\
676(560) \\
1460(57) \\
1660(54)\end{array}$ & $\begin{array}{c}<210 \\
223 \mathrm{sh} \\
240(2900) \\
590(290) \\
655 \mathrm{sh} \\
680(416)\end{array}$ \\
\hline $\mathrm{CoCl}_{4}^{2-} \quad \mathrm{T}_{\mathrm{d}}$ & $\begin{array}{l}\text { 613sh } \\
634(460) \\
666(650) \\
692(776) \\
>1700\end{array}$ & $\begin{array}{l}\text { 613sh } \\
633(484) \\
665(680) \\
692(820) \\
1735(89)\end{array}$ & $\begin{array}{c}<210 \\
217(2560) \\
233(4400) \\
613 \mathrm{sh} \\
633(464) \\
667(644) \\
692(770)\end{array}$ \\
\hline
\end{tabular}

is observed from DMSO to PC. For the second band, situated between 620 and $675 \mathrm{~nm}$, the shift could not be correlated with the solvents. The similarity of the $\mathrm{CoCl}^{+}$spectra in the three solvents indicates an identical structure and the spectrochemical sequence is that of the solvate. The d-d transition of this complex was calculated only in DMF and is situated at $1380 \mathrm{~nm}$.

3.4.3. Dichloro complex. Only one charge transfer band is calculated in PC. In the visible, $\mathrm{CoCl}_{2}$ has two absorption bands of unequal intensities at 610 and $680 \mathrm{~nm}$ in DMSO, at 606 and $670 \mathrm{~nm}$ in DMF, and a shoulder at $660 \mathrm{~nm}$ in both solvents. In PC, there is a clear bathochromic shift for all these bands with the first at $635 \mathrm{~nm}$ and the shoulder peak and the second maximum at 670 and $685 \mathrm{~nm}$, respectively. The similarity in DMSO and DMF indicates that solvation in these solvents is identical, which is logical since their solvating power is similar. The absence of significant absorption between 500 and $560 \mathrm{~nm}$ shows that the octahedral structure of cobalt in $\mathrm{CoCl}_{2}$ tends towards tetrahedral. This structural modification is confirmed by the existence in DMF of two bands in the IR (1480 and $1640 \mathrm{~nm}$ ), which could reflect an equilibrium between the two structures.

3.4.4. Trichloro complex. In the $\mathrm{UV}, \mathrm{CoCl}_{3}^{-}$is characterized by two intense maxima. The first is situated below $210 \mathrm{~nm}$ and is difficult to locate because of absorption due to 
electrolytes in PC. The second maximum of lesser intensity is situated at $240 \mathrm{~nm}$ with a shoulder at $223 \mathrm{~nm}$. In the visible, the electronic spectra of $\mathrm{CoCl}_{3}^{-}$in the three solvents show a band at $600 \mathrm{~nm}$, which undergoes a slight hypsochromic shift when going from DMSO to PC, a characteristic shoulder at $655 \mathrm{~nm}$, and a more intense maximum at $680 \mathrm{~nm}$. The absence of any absorption lower than $580 \mathrm{~nm}$ shows that cobalt is not octahedral in $\mathrm{CoCl}_{3}^{-}$. However, in the IR region, the calculated maxima in DMF (1460 and $1660 \mathrm{~nm}$ ) permit us to postulate, as in the case of $\mathrm{CoCl}_{2}$, a possible equilibrium between the two geometries.

3.4.5. Tetrachloro complex. There are two intense charge transfer bands of $\mathrm{CoCl}_{4}^{2-}$ in PC. The position of one is superimposed with the band for $\mathrm{CoCl}_{3}^{-}$below $210 \mathrm{~nm}$. The other is situated at $233 \mathrm{~nm}$; a shoulder exists at $217 \mathrm{~nm}$. In the visible spectrum, the electronic spectra of $\mathrm{CoCl}_{4}^{2-}$ is identical in the three solvents with maxima at 633, 666, and $692 \mathrm{~nm}$ and a shoulder at $613 \mathrm{~nm}$. In the solid, these positions have been determined for $\mathrm{T}_{\mathrm{d}}$ symmetry [16]. The $\mathrm{CoCl}_{4}^{2-}$ spectra in the solid and in solution are identical, and it is, therefore, independent of the solvent, expected since $\mathrm{CoCl}_{4}^{2-}$ is not solvated. Finally, the d-d transition band is at $1735 \mathrm{~nm}$.

\subsection{Structural modifications}

The octahedral structure for $\mathrm{Co}^{2+}$ is characterized by a weak, though well-defined, absorption maximum at $520 \mathrm{~nm}$ and a large band at $1350 \mathrm{~nm}$. These peaks are accompanied by weak bands between 600 and $750 \mathrm{~nm}$. On the other hand, the tetrahedral structure is characterized by no absorption below $600 \mathrm{~nm}$ and the presence of three absorptions of unequal intensities at 635,655 , and $690 \mathrm{~nm}$ for $\mathrm{CoCl}_{4}^{2-}$. In the IR region, the tetrachloro complexes have a single large band centered around $1700 \mathrm{~nm}$.

For intermediate complexes, the position of the calculated absorption maxima, the change of the direction of spectroscopic shift as a function of solvent and the degree of complexation show unambiguously that the octahedral configuration is broken as soon as $\mathrm{CoCl}^{+}$is formed.

The above observations are pertinent to the study of the solvent effects on the calculated electronic spectra of the complexes. In the three aprotic solvents studied, the chloro complexes have the same number of absorption bands in the visible, two for $\mathrm{CoCl}^{+}$, two for $\mathrm{CoCl}_{2}$, three for $\mathrm{CoCl}_{3}^{-}$, and three for $\mathrm{CoCl}_{4}^{2-}$.

The bathochromic shift $\delta$ for the principal absorption bands, nearest to red, are reported in table 6 . The shift as a function of the number of chloride ions coordinated to the metal is designated by $\delta_{n}$, whereas $\delta_{s}$ is the displacement with respect to the decreasing donor ability of the solvents.

For each solvent $\delta_{n}$ increases as the degree of the complexation of the metal. For cobalt(II) complexes, the value of $\delta_{n}$ is between 370 and $1700 \mathrm{~cm}^{-1}$. In case of each complex of the same rank, the shifts $\delta_{s}$ vary irregularly with respect to donor ability of the solvents. The maximum amplitude for $\delta_{S}$ is $1300 \mathrm{~cm}^{-1} ; \delta_{\mathrm{s}}$ is zero for the tetrachloro complexes.

The octahedral edifice of cobalt(II) is modified as soon as formation of $\mathrm{CoCl}^{+}$begins and that the configuration remains tetrahedral in the series of cobalt(II) chloro complexes. The symmetry is rigorously $\mathrm{T}_{\mathrm{d}}$ for $\mathrm{CoCl}_{4}^{2-}$. 
Table 6. Spectroscopic shift $\left(\mathrm{cm}^{-1}\right)$ of the principal absorption band $\left(\lambda_{\max }\right.$ in $\left.\mathrm{nm}\right)$.

\begin{tabular}{|c|c|c|c|c|}
\hline \multirow[b]{2}{*}{$\mathrm{CoCl}_{j}^{(j-2)-}$} & \multicolumn{3}{|c|}{ Principal absorption band } & \multirow[b]{2}{*}{$\delta_{s}\left(\mathrm{~cm}^{-1}\right)$} \\
\hline & DMSO & DMF & $\mathrm{PC}$ & \\
\hline$j=1$ & 670 & 620 & 675 & 1300 \\
\hline$j=2$ & 680 & 670 & 685 & 200 \\
\hline$j=3$ & 680 & 676 & 680 & 90 \\
\hline$j=4$ & 692 & 692 & 692 & 0 \\
\hline$\delta_{n}\left(\mathrm{~cm}^{-1}\right)$ & 480 & 1680 & 370 & \\
\hline
\end{tabular}

Notes: $\delta_{n}$ : the bathochromic shift with respect to the $n$ number of the coordinated ligands; $\delta_{s}$ : the spectroscopic shift with respect to the donor ability of the solvents.

\section{References}

[1] M. Elleb, J. Meullemeestre, M.J. Schwing, F. Vierling. Inorg. Chem., 19, 2699 (1980).

[2] M. Elleb, J. Meullemeestre, M.J. Schwing, F. Vierling. Inorg. Chem., 21, 1477 (1982).

[3] M.A. Khan, J. Meullemeestre, M.J. Schwing, F. Vierling. Polyhedron, 2, 459 (1983).

[4] C Amuli, J. Meullemeestre, M.J. Schwing, F. Vierling. Inorg. Chem., 22, 3567 (1983).

[5] C. Amuli, J. Meullemeestre, M.J. Schwing, F. Vierling. Inorg. Chem., 25, 856 (1986).

[6] C. Amuli, J. Meullemeestre, M.J. Schwing, F. Vierling. New J. Chem., 11, 27 (1987).

[7] M.A. Khan, J. Meullemeestre, M.J. Schwing, F. Vierling. Inorg. Chem., 28, 3306 (1989).

[8] S. Chafaa, T. Douadi, M.A. Khan, J. Meullemeestre, M.J. Schwing, F. Vierling. New J. Chem., 15, 39 (1991).

[9] S. Dali, F. Benghanem, M.A. Khan, J. Meullemeestre, M.J. Schwing, F. Vierling. Polyhedron, 10, 2529 (1991).

[10] E. Bentouhami, M.A. Khan, J. Meullemeestre, M.J. Schwing, F. Vierling. Polyhedron, 11, 2179 (1992).

[11] F. Djabi, J. Meullemeestre, F. Vierling, G. Bouet, M.A. Khan. Bull. Soc. Chim. Fr., 131, 53 (1994).

[12] A. Chiboub-Fellah, M.A. Khan, J. Meullemeestre, C. Spies, F. Vierling. Transition Met. Chem., 24, 135 (1999).

[13] H. Hubacek, B. Stancie, V. Gutmann. Monatsh. Chem., 94, 1118 (1963).

[14] V. Gutmann, G. Hampel, R.G. Masaguer. Monatsh. Chem., 94, 822 (1963).

[15] V. Gutmann, H. Bardy. Monatsh. Chem., 99, 763 (1968).

[16] F.A. Cotton, G. Wilkinson. Advanced Inorganic Chemistry, 5th Edn, p. 727, and 730, John Wiley \& Sons, New York (1988).

[17] A. Schriver. Bull. Soc. Chim. Fr., 1, 11 (1973).

[18] G. Licheri, G. Paschina, G. Piccaluga, G. Pinna. J. Chem. Phys., 79, 2168 (1983).

[19] T. Djekic, Z. Zivkovic, A.G.J. van der Ham, A.B. de Haan. Appl. Catal. A, 312, 144 (2006).

[20] K. Hirose. J. Incl. Phenom. Macrocycl. Chem., 39, 193 (2001).

[21] C. Lorber, R. Choukroun, J.P. Costes, B. Donnadieu. C.R. Chimie, 5, 251 (2002).

[22] J. Juillard. Pure Appl. Chem., 49, 885 (1977).

[23] B. Gossé, A. Denat. J. Electroanal. Chem. Interfacial Electrochem., 56, 129 (1974).

[24] H.A. Flaschka. EDTA Titrations, p. 80, Pergamon Press, Oxford (1964).

[25] F. Vierling, M.J. Schwing, J. Meullemeestre. Spectra 2000, 79, 25 (1982).

[26] O. Benali-Baïtich, E. Wendling. J. Inorg. Nucl. Chem., 37, 1217 (1975).

[27] Z.Z. Hugus, A.A. El-Awady. J. Phys. Chem., 75, 2957 (1971).

[28] J. Byé, R. Hugel, G. Schorsh, R. Strosser. Bull. Soc. Chim. Fr., 1146 (1964).

[29] V. Gutmann. Coordination Chemistry in Non-aqueous Solutions, Springer Verlag, Vienna, New York (1968).

[30] M.A. Khan, M.J. Schwing-Weill. Inorg. Chem., 15, 2202 (1976).

[31] M.A. Khan, J. Meullemeestre, M.J. Schwing, F. Vierling. Inorg. Chem., 28, 3306 (1989).

[32] M.A. Khan, J. Meullemeestre, M.J. Schwing, F. Vierling. Polyhedron, 9, 2613 (1990). 